\title{
Tactile narratives about an architecture's ornaments
}

\author{
Adriane Borda \\ Universidade Federal de Pelotas, Brasil \\ adribord@hotmail.com
}

\begin{abstract}
This study experiments a process of production of tactile representations of architectural elements of a nineteenth century mansion, house to a university museum: Museu do Doce, Pelotas, RS. The Museum uses the concept of Universal Design to guide its direct and/or mediated communication solutions. The house is distinguished by ceilings of ornamental stuccoes, evidently perceived only by the sense of sight. To describe them, a set of representations is being produced, using 3D scanning and digital fabrication technologies, using formal decomposition, and different scales, to construct a narrative to be understood by touching.
\end{abstract}

Keywords: Tactile models; Universal Design; Architectural heritage; Representation technologies; Stuccoes.

\section{Introdução}

Este estudo tem como campo de observação e experimentação a produção e exposição de representações táteis de elementos que adornam tetos e paredes de uma edificação, de interesse patrimonial, que abriga uma instituição museológica brasileira de caráter público e universitário: o Museu do Doce, Pelotas, RS de responsabilidade da Universidade Federal de Pelotas, UFPel.

A edificação se refere a um casarão, ilustrado à esquerda da Figura 1, erguido em 1878 e tombado em 1977 pelo Instituto de Patrimônio Histórico e Artístico Nacional sob a justificativa de ser um dos primeiros exemplares de estilo eclético no Brasil. De acordo com Santos (2007), este estilo arquitetônico se manifestou na cidade de Pelotas entre 1870 e 1930. O casarão, como um de seus diferenciais, tem seus tetos em estuques ornamentais, percebidos evidentemente apenas pelo sentido da visão. $O$ tipo de estuque pode ser exemplificado pela imagem da direita da Figura 1, que se refere ao teto de uma das salas do Casarão, precisamente a sala da Música, cômodo das duas portas-janela da direita da fachada principal. As figuras representadas neste forro, assim como as dos demais cômodos, denunciam a função do ambiente. Os quatro cantos do estuque referido estão adornados por figuras alegóricas, uma feminina e um querubim, ambas com instrumentos musicais, sempre envoltos em folhagens e folhas de acanto.

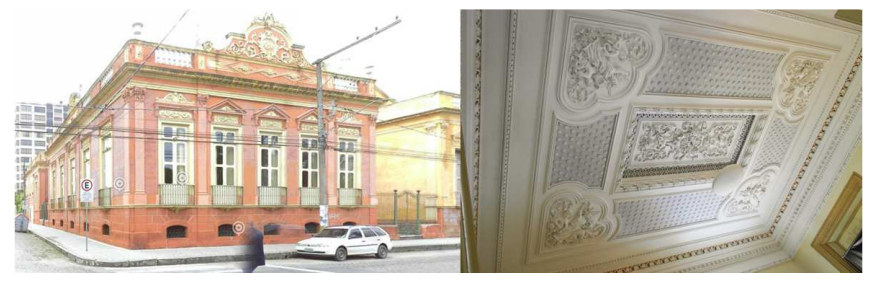

Figura 1: Museu do Doce, Pelotas, RS, fachadas principais e estuque da sala de Música. Fonte: acervo GEGRADI, FAURB, UFPel
Santos (2007), afirma que muitas das figuras que adornam este tipo de estuque, chegavam ao porto de Pelotas em grandes quantidades. Outras eram copiadas ou criadas e multiplicadas em ateliês especializados que se estabeleceram na cidade. Corona e Lemos (1972), elucidam que as figuras podiam ser executadas de maneira escultórica ou utilizandose de moldes. No caso aqui particularizado, figuras foram criadas especificamente para este Casarão. A diversidade destas figuras inclui formas geométricas, normalmente compondo os enquadramentos e frisos, e formas orgânicas ou escultóricas, em sua maioria para caracterizar figuras alegóricas, muitas vezes aladas, plantas, como folhagens, flores, guirlandas e frutas, animais e formas diversas, simbólicas ou incluindo representações de objetos do cotidiano, relativos aos hábitos, crenças e ideologias dos proprietários. A composição destas figuras, muitas vezes sobrepostas e intrincadas, atribui complexidade à descrição da forma por meio de modelos táteis.

A produção destes modelos foi inicializada durante o ano 2016, no âmbito do Programa de Extensão Museu do Conhecimento para Todos, PROEXT junto à UFPel e se estabelece como ação continuada para apoiar as atividades do Museu do Doce. A equipe envolvida se constituiu de maneira interdisciplinar, agregando recursos humanos das áreas de Arquitetura e Urbanismo, Museologia, Conservação e Restauro, Terapia Ocupacional, Cinema, Design Gráfico e Design Digital, incluindo estudantes de graduação e pósgraduação. Em todas as suas fases de desenvolvimento (formulação, proposição de metodologias e avaliação dos resultados) o programa contou com a parceria da Escola Louis Braille e do Centro de Reabilitação Visual, ambos situados na cidade de Pelotas.

Este estudo avança no emprego do método da adição gradual da informação (AGI), o qual foi originalmente constituído para a descrição de fotografias (Borda et al, 2012) e transposto para a representação de espaços e elementos de arquitetura (Dalla Vecchia et al 2015). Este método se refere ao projeto de um conjunto de modelos derivados da decomposição de um objeto, em diferentes escalas, de acordo com a complexidade da forma para ser compreendida por pessoas 
com deficiência visual. Para o caso em questão, as geometrias envolvidas são complexas, constituindo-se como desafios para a área de representação.

\section{Os procedimentos metodológicos}

O desenvolvimento das representações táteis tem partido de uma revisão bibliográfica que inclui temas que abordam desde as questões conceituais, perceptivas, metodológicas e regimentais até as tecnológicas que possam envolver todo o processo, do projeto à disponibilização e uso das mesmas. Um dos principais referenciais utilizados para sensibilizar a equipe de produção das representações, que se constitui de estudantes de arquitetura, tem sido Pallasma (2011). Nesta direção, em trabalho anterior (Peronti, Borda e Veiga, 2016), observou-se a edificação representada em sua qualidade multissensorial tendo-se este estudo aqui descrito como um desdobramento do mesmo. Sobretudo, tem se valido da pesquisa experimental, agregando um interesse formativo neste campo de conhecimento, que investe na construção de uma cultura para a inclusão, com práticas projetuais que buscam superar obstáculos (resilience design), neste caso específico, proporcionando acessibilidade à informação.

\section{O desenho universal como marco teórico e metodológico}

A adoção do conceito de Desenho Universal, para guiar a ocupação dos espaços expositivos, é estabelecida no próprio regimento da instituição museológica em questão. Sob a ótica de Ornstein (2010), o uso deste conceito implica a necessidade de observar: I - uso equitativo; II - uso flexível; III - uso simples e intuitivo; IV - informação de fácil percepção; V - segurança; VI - esforço físico mínimo; VII - dimensionamento para acesso e uso abrangente (ORNSTEIN, 2010, p. 15-21). Desta maneira, o processo de projeto das representações fica atento a estes sete princípios e conta com a colaboração de um consultor, estudante de pós-graduação da UFPel e membro da equipe do Projeto.

\section{O método de adição gradual da informação: AGI}

O método, nomeado como "adição gradual da informação", AGI, foi estruturado e experimentado para a descrição de fotografias, por meio de esquemas e maquetes táteis (Borda et al, 2012; Veiga et al, 2013). Já havia sido transposto para o mesmo tipo de propósito aqui declarado: descrição de objetos tridimensionais, aplicado aos objetos de arquitetura de interesse patrimonial (Dalla Vecchia et al, 2015).

As representações, produzidas pelo método AGI, objetivam contribuir com a composição de narrativas próprias de ações educativas e culturais. Este método propõe considerar a necessidade de desmembrar informações complexas para serem compreensíveis pelo sentido do tato, por meio de camadas de informação, em um crescente de adição de elementos formais. Os recursos táteis passam a compor uma narrativa, sendo que, necessariamente, associados a outros canais complementares de comunicação, como a mediação presencial ou mesmo a audiodescrição.

\section{As tecnologias empregadas}

A necessidade de produzir modelos, digitais e logo físicos, de geometrias complexas, como a destes elementos ornamentais inacessíveis naturalmente ao tato, provocou a apropriação de tecnologias avançadas de representação, por possibilitarem a otimização do tempo de produção e de viabilização da fidelidade dos modelos.

\section{Para a tradução do físico ao digital: por escaneamento 3D e fotogrametria}

As tecnologias empregadas referiram-se, inicialmente, ao escaneamento tridimensional (3D) por laser terrestre, para a obtenção automatizada do modelo digital de todo o edifício, externa e internamente. Todo o processo de reconhecimento, experimentação e produção destes modelos a partir do escaneamento a laser resultou da oportunidade de estabelecer uma parceria com um empresário pelotense, Engenheiro Diego Sacco Silveira, proprietário do equipamento, processo descrito em Borda et al (2016). Ao longo de 2016, os modelos digitais foram sendo gerados no âmbito de ações formativas, envolvendo estudantes de arquitetura e urbanismo de graduação e pós-graduação. 0 produto do escaneamento $3 \mathrm{D}$ é denominado nuvem de pontos, uma representação de pontos, no espaço digital, dispostos em um único sistema de referência. São pontos capazes de informar, em conjunto, a forma de todas as superfícies expostas ao laser emitido pelo equipamento (responsável por localizar cada um dos pontos capturados). Para criação da nuvem completa do edifício, foi necessária a realização de diversos escaneamentos tanto na parte interna como externa do edifício. O resultado consistiu em mais de 2 milhões e 700 mil pontos que representam com exatidão a arquitetura do Casarão. A Figura 2 ilustra esta representação permitindo visualizar grande parte do conjunto de estuques a ser narrado, envolvendo nove cômodos do corpo principal do casarão.

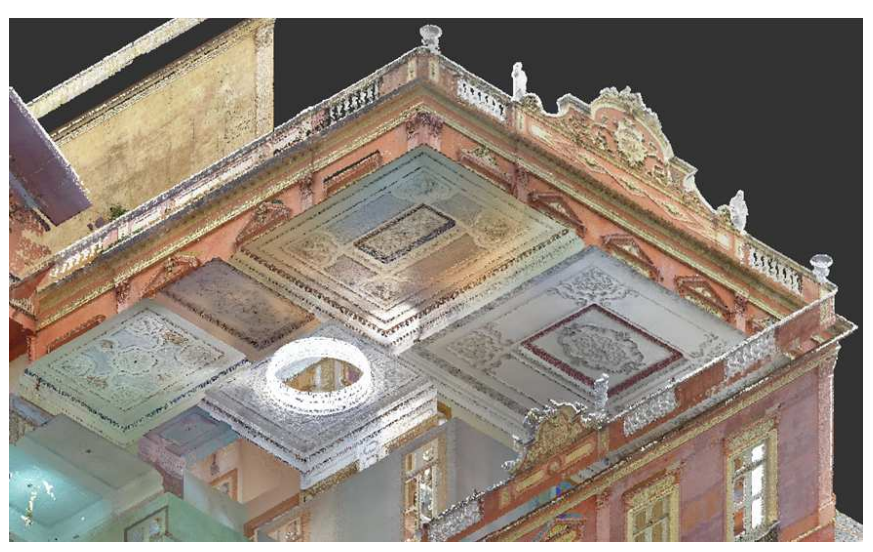

Figura 2: Nuvem de pontos que registra a geometria da superfície visível de cada um dos estuques da edificação que abriga o Museu do Doce, Pelotas, RS, disponibilizada pelo Eng. Diego Silveira. Fonte: acervo GEGRADI, FAURB, UFPel

Entretanto, a nuvem obtida pelo escaneamento realizado carece de nitidez ao nível de detalhe, tendo sido conveniente utilizar também, como técnica complementar, a fotogrametria 
digital. Desta maneira, para um ornamento específico, obtémse um conjunto de fotos, sob diferentes pontos de vista, para deduzir a localização de cada ponto de sua superfície. Esta informação gera também uma nuvem de pontos, porém já associada a uma geometria, de maneira automatizada.

Sendo assim, vários dos modelos digitais que facilitaram a execução dos esquemas e maquetes táteis são produtos diretos do processamento destas nuvens, seja pelo escaneamento ou por fotogrametria. Outros, indiretamente, derivam desta informação, utilizando-se de imagens técnicas, como projeções ortogonais destas nuvens. Sobre as vistas das figuras que adornam os tetos ou as fachadas são realizados desenhos vetorizados dos contornos aparentes. Desta maneira as representações respeitam as proporções efetivas de tais figuras.

\section{Para a tradução do digital ao físico: por fabricação digital}

Em um segundo momento, a informação digital passa a ser tratada para o uso das técnicas de fabricação digital. A tecnologia utilizada para a impressão 3D utilizada refere-se à deposição de camadas de material plástico fundido, exigindo a configuração de um modelo digital sólido. Sendo assim cada um dos pontos da nuvem passa a ser vértice de triângulos, configurando uma densa malha que representa a superfície de cada elemento arquitetônico escaneado para logo, passar de modelo de superfície para modelo sólido. A imagem da direita da figura 3 ilustra modelos impressos que passaram por este processamento da nuvem de pontos. Os elementos que adornam as fachadas estão sendo produzidos para uma maquete tátil de todo o Casarão, tendo-se uma representação por processos mistos: impressão 3D e corte a laser. Já a sequencia das imagens da esquerda da mesma figura, ilustram as etapas de representação de uma gárgula, desde a fotografia, passando pela densa malha obtida por fotogrametria digital e logo o elemento já impresso em 3D.

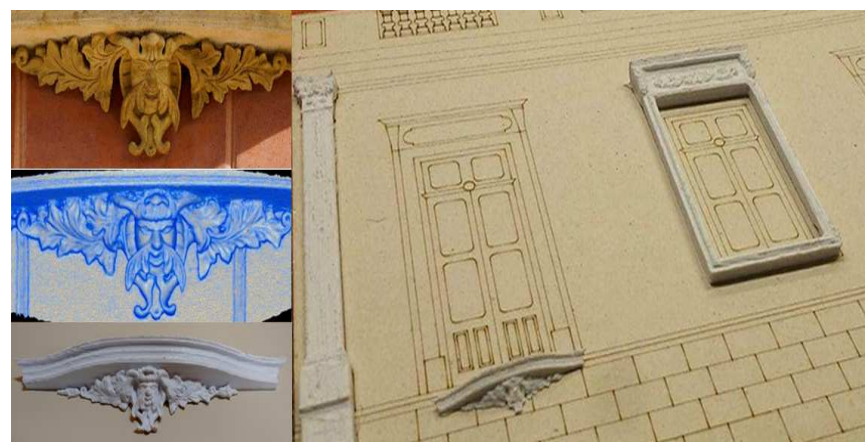

Figura 3: Representações táteis que explicam o tipo e a localização dos adornos das fachadas do casarão, executadas pelas acadêmicas de arquitetura Karine Chalmes e Cláudia Freitas. Fonte: acervo GEGRADI, FAURB, UFPel

O corte da madeira e do acrílico, controlado digitalmente, conforme as linhas de contorno das formas das fachadas, das plantas e de cada um dos elementos constitui o método de produção da maioria das representações do acervo.

\section{A construção das narrativas táteis}

Inicialmente os projetos dos modelos táteis foram orientados para apoiar essencialmente as narrativas pré-existentes no Museu. Entretanto, a dinâmica de decomposição proposta pelo método AGI passou a indicar outras possibilidades, configurando-se tipos diversos de narrativas.

\section{0 apoio às narrativas pré-existentes}

Os discursos advindos da museologia facilitam a compreensão do edifício como suporte de memória da história da cidade de Pelotas e guiam a caracterização das camadas de informação a serem criadas para cada um dos elementos. Mas, sobretudo, é da interação com o público deficiente visual e da abordagem da terapia ocupacional, que advém o controle e determinação da quantidade e qualidade de informação a ser adicionada em cada camada. Sob a terminologia da representação, além da decomposição formal importa a delimitação da escala, particularizando uma sequencia de modelos para um único elemento, de acordo com o propósito da narrativa a ser construída. Por exemplo, cada um dos estuques dos tetos da edificação exige uma sequencia de modelos que pode variar desde a escala $1: 50$, de todo 0 elemento, até $1: 1$. Isto pode ser ilustrado pelo conjunto de imagens da Figura 4. As representações se referem aos estuques do hall de entrada. A peça impressa em 3D reproduz toda a rugosidade do estuque do teto. Ao lado tem-se um jogo de encaixe produzido por corte a laser a partir de uma vetorização do contorno das figuras. As imagens da segunda linha demonstram o conjunto que compõe a narrativa para descrever o medalhão que contém o monograma dos proprietários.

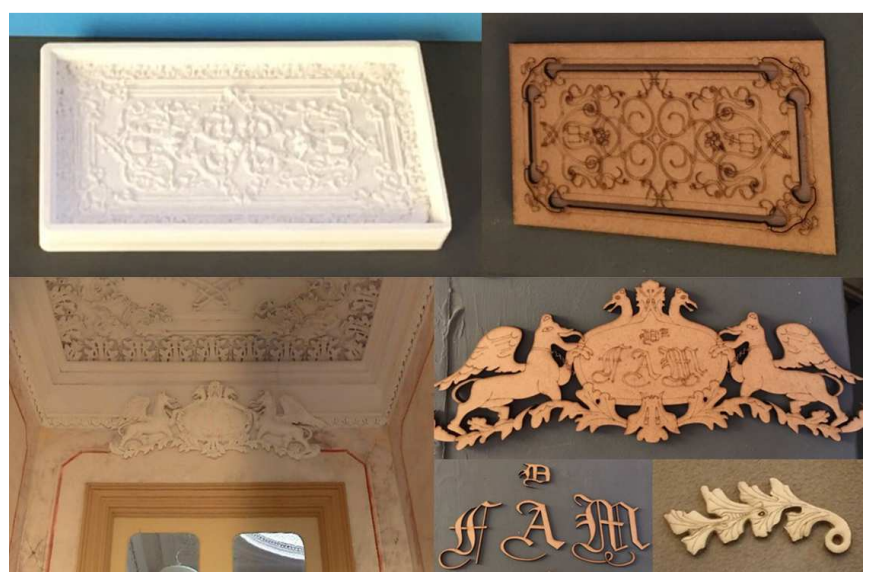

Figura 4: Esquemas táteis relativos ao medalhão com monograma dos proprietários, e a uma folha de acanto, executados pelas acadêmicas de arquitetura Amanda Cardoso e Cláudia Freitas, respectivamente. Fonte: acervo GEGRADI, FAURB, UFPel

\section{As camadas adicionais de informação}

O processo de vetorização (desenho digital de cada uma das linhas que representam as figuras) envolve a aplicação de conhecimentos básicos de geometria plana, técnicas de representação e de compreensão das lógicas de organização formal da arquitetura em questão. Desta maneira, a atividade contribui para o processo formativo dos estudantes envolvidos 
na produção, promovendo intercâmbios especialmente entre áreas intrínsecas ao saber especializado de arquitetura. $\mathrm{O}$ ato de representar, nas diferentes escalas do objeto de arquitetura, motiva o interesse em compreender os conceitos de projeto, os processos construtivos associados a este conceito, as terminologias próprias de cada um dos elementos representados. $O$ processo produtivo dos esquemas e maquetes táteis tem registrado assim a colaboração de pesquisadores do Núcleo de Estudos em Arquitetura Brasileira, NEAB, da FAURB, auxiliando no aperfeiçoamento da linguagem a ser utilizada junto aos discursos de mediação do Museu para especificar a nomenclatura de cada um dos elementos de arquitetura.

Sob a abordagem da geometria, os procedimentos analíticos, para otimizar a representação e a execução dos esquemas e maquetes, por si só, exigem a compreensão da lógica compositiva de cada elemento arquitetônico. Esta lógica envolve diferentes tipos de simetrias e recursões, de relações proporcionais e concordâncias que revelam a qualidade técnica dos processos de projeto de cada figura. Este conhecimento especializado, assim como aquele relativo à terminologia arquitetônica de cada elemento, está sendo produzido e agregado à representação, porém, sua exposição e incorporação à narrativa da instituição poderão ser opcionais, como camada de informação, caso o visitante queira acessá-lo.

O conjunto de representações da Figura 5 exemplifica os diferentes tipos de narrativas sobre um mesmo elemento: o estuque da sala da música. Algumas subtraem informação, como as peças em acrílico colorido que objetivam demonstrar os formatos que enquadram cada figura representada, como um jogo de encaixe ou ainda as que adicionam o apelo visual, em MDF. A segunda linha da figura ilustra a narrativa que disserta sobre um detalhe, desde a sua rugosidade à possibilidade de individualizar os elementos simbólicos associados ao uso atribuído ao espaço. A representação do instrumento musical, assim como das diversas figuras individualizadas de cada estuque, compõe um jogo para o público infantil. Ao ingressar no Museu recebem algumas destas figuras e são motivados a encontrar cada uma delas ao longo da visita. As imagens das duas últimas linhas da Figura 5 registram, à esquerda, os esquemas para gerar uma camada de informação especializada sobre a lógica de organização formal. É possível identificar propósitos de posições exatas de cada detalhe, utilizando-se de simetrias, e as demais estratégias clássicas de composição, como o uso de triângulos equiláteros como polígonos envolventes e regramento de paralelismos e perpendicularidades. Ainda se evidencia o emprego da lógica de elipses na proporção de raiz como moldura para vários elementos. Abaixo e à direita, da mesma Figura 5, constitui-se uma narrativa sobre estas informações geométricas, de interesse formativo para estudantes e profissionais de arquitetura, artes e design. Disponibiliza-se um esquema, podendo ser configurado como um jogo de costura. Para isto, foram realizados orifícios estratégicos sobre a representação propondo a reprodução deste rigoroso traçado geométrico. Ainda, a peça em acrílico transparente evidencia a lógica das elipses.

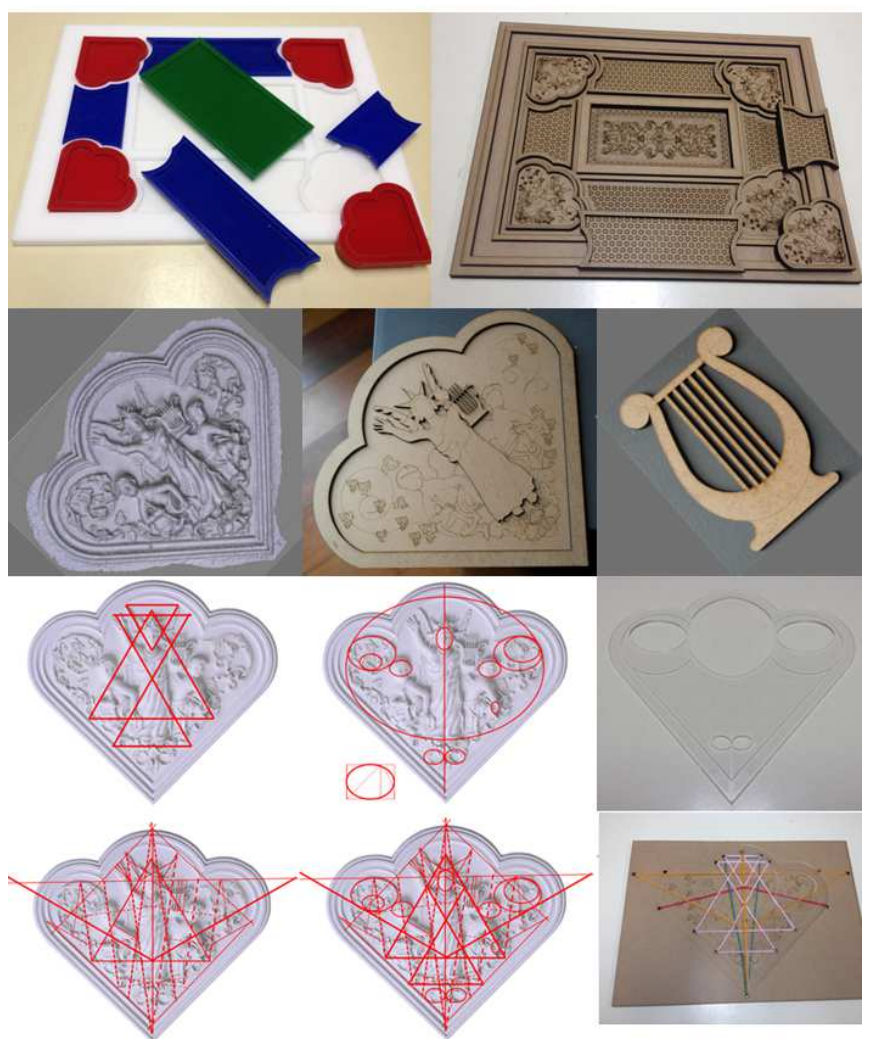

Figura 5: Esquemas táteis relativos ao estuque da sala da música, executados pelo acadêmico de arquitetura Gabriel Lopes. Fonte: acervo GEGRADI, FAURB, UFPel

\section{As representações derivadas}

A Figura 6 exemplifica de que maneira o método de decomposição da informação tem promovido 0 desenvolvimento de projeto e execução de produtos derivados do conjunto das representações. A partir de cada narrativa sobre um estuque, executada por um estudante de arquitetura, foi projetada uma linha de produtos, de caráter lúdico (jogos), decorativo ou utilitário. A intenção é de que esta produção, por sua materialidade possa se constituir como um suporte de memória a ser adquirido pelo visitante do museu.

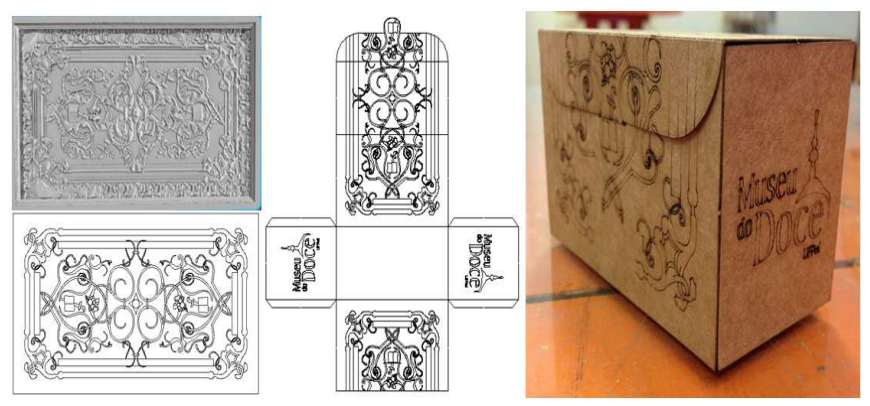

Figura 6: exemplificação de subproduto das representações: caráter lúdico e/ou utilitário, relativo ao estuque do hall, executado pela acadêmica de arquitetura Amanda Cardoso. Fonte: acervo GEGRADI, FAURB, UFPel 


\section{Resultados e discussão}

Como resultado do estudo tem-se a disponibilização de um conjunto de representações que caracterizam narrativas táteis para descrever os ornamentos de uma edificação de interesse patrimonial.

Ao relatar o processo de produção das representações foi sendo demonstrado como o método da adição gradual da informação, AGI, foi aplicado e de que maneira oportunizou caracterizar diferentes tipos de narrativas (com ênfase em aspectos lúdicos, informativos, utilitários, decorativos). Todas elas por propor a interação por meio do corpo, de maneira tátil, podem auxiliar na intensificação da experiência e facilitar a apreensão e constituição das memórias permanentes. Assim como, a partir das réplicas ou souvenires relativos às representações, constituírem-se como suportes de memória sobre a experiência cultural. O método em si foi constituído sob o propósito de configuração de um desenho universal, capaz de eliminar obstáculos que impeçam à compreensão da informação (neste caso, sobre a forma dos elementos ornamentais). E, por isto, os projetos buscaram adotar estratégias diferenciadas, para atingir aos diversos públicos que adentram a uma instituição museológica de acesso gratuito.

Estes resultados podem ser evidenciados quando interpretados à luz dos sete princípios do desenho universal estabelecidos por Ornstein (2010), a saber:

I - quanto ao uso equitativo: as representações tem sido exploradas tatilmente, com motivação, pelos visitantes em geral, de qualquer faixa etária, nível cultural ou diferenças cognitivas e/ou físicas. As representações, apesar de subtraírem informação, para simplifica-la e ser perceptível ao tato, agregam 0 apelo visual (desenhos dos contornos aparentes das figuras) e auditivo (seja por mediação direta ou por áudio-descrição). Desta maneira, promovem a inclusão de todos.

II - quanto ao uso flexível: os diferentes propósitos implícitos aos tipos de representações produzidos atribui flexibilidade ao uso adequando-se a momentos culturais de caráter educativo, lúdico, informativo; por outro lado, frente à possibilidade de expandir o uso das representações para além do espaço do Museu, como está sendo efetivada a ação "patrimônio vai à escola". A possibilidade de fabricação em série e parametrizada quanto às escalas de representação, com a reprodução, por corte a laser, em diferentes materiais, como papel, MDF e acrílico (tem-se contado com a doação de restos de acrílico de empresas de corte em escala comercial) permite a disponibilização destas narrativas para motivar a visitação ao Museu ao mesmo tempo servirem de material didático para o ensino fundamental e médio.

III - quanto ao uso simples e intuitivo; considera-se que o caráter lúdico, naturalmente atribuído às representações em escala (maquetes) adicionado ao sistema de encaixes, e de estratégia de caracterização como um jogo deixa simples e intuitivo o uso destas representações;

IV - quanto à informação de fácil percepção: observa-se nos visitantes a facilidade em associar diretamente as representações, percebendo a lógica do desmembramento da informação com a variação de escala e decomposição formal.
Logicamente, no caso de pessoas deficientes visuais, para atender a estes princípios existe uma sequencia de apresentação das representações, que pode variar com as estratégias didáticas do mediador. Ou parte do mais simples para chegar a explicar a rugosidade dos estuques ou no sentido inverso.

$\mathrm{V}$ - quanto à segurança; o modo de produção dos modelos e os materiais empregados permitem atribuir qualidades relativas a este princípio. As peças produzidas por impressão 3D, em PLA, ou por corte a laser, em acrílico, facilitam o processo de higienização exigido para a exposição ao público. Ou, quando em MDF, pelas facilidades de produção, o processo de reposição pode ser imediato ao constatar algum tipo de deterioração e risco para a segurança no uso.

$\mathrm{VI}$ - quanto ao esforço físico mínimo; entende-se o atendimento a este princípio quando se faz referência à facilitação ao trabalho dos mediadores para explicar a lógica dos elementos ornamentais a partir das narrativas táteis disponibilizadas. Assim como ao observar o quanto as estratégias de caráter lúdico facilitam a ação educativa própria de uma instituição museológica.

VII - quanto ao dimensionamento para acesso e uso abrangente. As narrativas tem observado a escala adequada para cada tipo de informação e estão disponibilizadas, na medida do possível, permanentemente junto aos ornamentos que representam. Com isto, promovem a curiosidade sobre suas lógicas formais conectadas à história do lugar e de seus significados sociais e culturais. O uso abrangente, como destacado anteriormente pode estar assegurado pela diversidade de representações em seus apelos de uso: lúdico, informativo ou decorativo.

As narrativas mais fortemente de caráter lúdico, direcionamse ao público em geral, por apresentarem a informação histórica e cultural de maneira simples e intuitiva. As de caráter utilitário, pela proposta de se integrarem ao cotidiano, seja como objetos decorativos ou propriamente de uso pessoal, constituem-se como suportes de memória para a experiência vivida junto ao Museu. As narrativas que enfatizam o caráter científico como as camadas de informação sobre as terminologias arquitetônicas de cada elemento, ou sobre organizações geométricas implícitas a cada figura, são acessíveis de maneira opcional, atendendo aos visitantes mais curiosos e com certo tempo para desfrutar de informações mais detalhadas. O uso das tecnologias de representação e de fabricação digitais, especialmente por fazer parte de um processo contínuo de formação, inicialmente exigiu um tempo maior de planejamento, de constituição de uma infraestrutura, de apropriação e de sistematização dos métodos de produção. Entretanto, o acervo gerado, dos diferentes formatos de representações físicas e digitais, exposto à dinâmica do ambiente universitário (constante renovação da equipe, especialmente de estudantes), e, a interação com a comunidade de visitantes, provoca cada vez mais a emergência de novas soluções. Frente a isto, tem-se a perspectiva de ter gerado uma dinâmica de produção de narrativas táteis apropriada ao apoio da instituição museológica em questão: tem-se disponível uma nuvem de pontos que corresponde a um levantamento preciso da edificação; utiliza-se de técnicas de fotogrametria para a complementação da informação de determinados detalhes; a fabricação digital facilita o redesenho e atribui autonomia e viabilidade à produção particularizada. 
Ainda, o fato de individualizar cada figura do estuque para a experiência tátil tem intensificado a interação dos visitantes do Museu que por vezes adicionam informação às narrativas dos mediadores, auxiliando a decifrar significados implícitos às representações e contribuindo para aperfeiçoar o discurso fundamentado em lógicas científicas. Salienta-se ainda que a proposta lúdica de distribuir ao público infantil visitante, ao ingressar no Museu, as representações das figuras extraídas dos estuques, para que descubram onde estão, provoca um maior envolvimento e interesse em compreender a lógica da ornamentação.

\section{Considerações finais}

Este estudo problematizou um processo de produção de representações táteis de elementos arquitetônicos de um edifício do século XIX, de interesse patrimonial e sede de uma instituição museológica universitária. O processo de produção esteve guiado pelo conceito de Desenho Universal, adotado pela própria instituição para nortear suas soluções de comunicação direta e/ou por mediação. O método AGI (adição gradual da informação) foi empregado, produzindo-se as narrativas táteis sobre os ornamentos. Desta maneira, um conjunto de esquemas e maquetes foi produzido para cada elemento a ser narrado, utilizando-se de sua decomposição: identificando elementos mínimos para compor uma narrativa gradual para a compreensão do todo. Reforçou-se a conveniência de emprego deste método, frente aos preceitos do desenho universal.

O estudo permitiu compreender que um olhar atento, interdisciplinar, integrado e dirigido às ações educativas, extensionistas e de investigação, constituído no âmbito de um Museu universitário, atribui compromisso e liberdade para a criação e experimentação. Entende-se que as soluções até então encontradas ampliam o repertório de estratégias para a inclusão de diferentes públicos, especialmente por se apresentarem com ênfases diferenciadas: de maneira lúdica, científica e utilitária, mas cada uma delas incluindo aspectos das demais.

\section{Agradecimentos}

À equipe de profesores e bolsistas do Projeto de Extensão Museu do Conhecimento para todos, (PROEXT, UFPel), em particular à coordenadora geral, Francisca Michelon, e ao consultor sobre o uso das representações, Lheandro Freitas Pereira, estudante de pósgraduação da UFPel.

Ao Engenheiro Diego Sacco Silveira, que desenvolveu o trabalho de escaneamento $3 \mathrm{D}$ e apoiou todo o processo formativo dos bolsistas para o tratamento de nuvem de pontos e para o emprego da fotogrametría.

À equipe de professores e bolsistas do GEGRADI (Grupo de ensino/aprendizagem de Gráfica Digital, FAURB/UFPel, que apoiou o desenvolvimento de todo o estudo.

\section{Referências}

Corona, Eduardo \& Lemos, Carlos.(1972) Dicionário da arquitetura brasileira. São Paulo: EDART.

Noble, A. W., Santos, J., Santos, C. A. (2011). Elementos funcionais e ornamentas no ecletismo de Pelotas, 1870-1931. Estuques. In: V Seminário Internacional em Memória e Patrimônio. Pelotas: PPG em Memória Social e Patrimônio Cultural.

Borda, A.; Veiga, M.; Nicoletti, I.; Michelon, F. (2012). Descrição de Fotografias a partir de modelos táteis: ensaios didáticos e tecnológicos. 3o Seminário Internacional Museografia e Arquitetura de Museus. Conservação e técnicas sensoriais, Rio de Janeiro, UFRJ.

Borda, A.; Silveira, D.; Medina, A.; Dalla Vecchia, L. (2016). Pontos (de vista) sobre o patrimônio: entre o escaneamento e a fotogrametria In: XX Congreso de la Sociedad Iberoamericana de Gráfica Digital, Buenos Aires. Blucher Design Proceedings. São Paulo: Editora Blucher, v.3. p.651 - 556

Dalla Vecchia, L.; Borda, A.; Pires, J.; Veiga, M.; Vasconselos, T.; Borges, L. (2015) Tactile models of elements of architectural heritage: from the building scale to the detail The next city - New technologies and the future of the built environment [16th International Conference CAAD Futures 2015. Sao Paulo, Electronic Proceedings, pp. 434-446.

Ornstein, S.W. (org.).(2010). Desenho universal: caminhos da acessibilidade no Brasil. São Paulo: Annablume.

Pallasma, J.(2011). Os olhos da pele: Arquitetura e os sentidos. Trad: Alexandre Salvaterra. Porto Alegre: Bookman, 68p.

Santos, C. A. (2007). Ecletismo na fronteira meridional do Brasil: 1870-1931. Tese (Doutorado em Arquitetura e Urbanismo - Área de Conservação e Restauro) Universidade Federal da Bahia, Salvador .

Veiga, M.; Borda, A.; Michelon, F.; Lebedeff, T. (2013). Atribuição de Acessibilidade à Fotografia através da Restituição e Desconstrução da Tridimensionalidade. XVII Conference of the Iberoamerican Society of Digital Graphics, 17., Valparaíso, Chile, SIGRADI: Knowledge-based Design 2013, Universidad Técnica Federico Santa María, 2013.p.449.

Peronti, G.; Borda, A.; Veiga, M. (2016). A representação do espaço de arquitetura por meio de dispositivos táteis: uma revisão conceitual e tecnológica In: XX Congreso de la Sociedad Iberoamericana de Gráfica Digital, Buenos Aires. Blucher Design Proceedings. São Paulo: Editora Blucher, 2016. v.3. p.561 - 566 